\title{
Early Biofilm Formation on UV Light Activated Nanoporous $\mathrm{TiO}_{2}$ Surfaces In Vivo
}

\author{
Nagat Areid $\left(\mathbb{D},{ }^{1}\right.$ Eva Söderling $\mathbb{D}^{2},{ }^{2}$ Johanna Tanner $\mathbb{D},{ }^{3,4}$ \\ Ilkka Kangasniemi, ${ }^{5}$ and Timo O. Närhi ${ }^{6,7}$ \\ ${ }^{1}$ PhD Student, Department of Prosthetic Dentistry and Stomatognathic Physiology, Institute of Dentistry, University of Turku, Finland \\ ${ }^{2}$ Professor, Institute of Dentistry, University of Turku, Finland \\ ${ }^{3}$ Senior Lecturer, Department of Prosthetic Dentistry and Stomatognathic Physiology, Institute of Dentistry, \\ University of Turku, Finland \\ ${ }^{4}$ Department of Oral and Maxillofacial Diseases, Turku University Hospital, Turku, Finland \\ ${ }^{5}$ Adjunct Professor, Turku Clinical Biomaterials Centre, University of Turku, Finland \\ ${ }^{6}$ Professor, Department of Prosthetic Dentistry and Stomatognathic Physiology, Institute of Dentistry, University of Turku, Finland \\ ${ }^{7}$ Chief Hospital Dentist, Department of Oral and Maxillofacial Diseases, Turku University Hospital, Turku, Finland
}

Correspondence should be addressed to Nagat Areid; nmaare@utu.fi

Received 7 September 2018; Accepted 8 November 2018; Published 22 November 2018

Academic Editor: Feng-Huei Lin

Copyright (c) 2018 Nagat Areid et al. This is an open access article distributed under the Creative Commons Attribution License, which permits unrestricted use, distribution, and reproduction in any medium, provided the original work is properly cited.

\begin{abstract}
Purpose. To explore early $S$. mutans biofilm formation on hydrothermally induced nanoporous $\mathrm{TiO}_{2}$ surfaces in vivo and to examine the effect of UV light activation on the biofilm development. Materials and Methods. Ti-6Al-4V titanium alloy discs $(\mathrm{n}=40)$ were divided into four groups with different surface treatments: noncoated titanium alloy (NC); UV treated noncoated titanium alloy (UVNC); hydrothermally induced $\mathrm{TiO}_{2}$ coating (HT); and $\mathrm{UV}$ treated titanium alloy with hydrothermally induced $\mathrm{TiO}_{2}$ coating (UVHT). In vivo plaque formation was studied in 10 healthy, nonsmoking adult volunteers. Titanium discs were randomly distributed among the maxillary first and second molars. UV treatment was administered for 60 min immediately before attaching the discs in subjects' molars. Plaque samples were collected $24 \mathrm{~h}$ after the attachment of the specimens. Mutans streptococci (MS), non-mutans streptococci, and total facultative bacteria were cultured, and colonies were counted. Results. The plaque samples of NC (NC + UVNC) surfaces showed over 2 times more often $S$. mutans when compared to $\mathrm{TiO}_{2}$ surfaces (HT + UVHT), with the number of colonized surfaces equal to 7 and 3 , respectively. Conclusion. This in vivo study suggested that $\mathrm{HT} \mathrm{TiO}_{2}$ surfaces, which we earlier showed to improve blood coagulation and encourage human gingival fibroblast attachment in vitro, do not enhance salivary microbial (mostly mutans streptococci) adhesion and initial biofilm formation when compared with noncoated titanium alloy. UV light treatment provided Ti-6Al-4V surfaces with antibacterial properties and showed a trend towards less biofilm formation when compared with non-UV treated titanium surfaces.
\end{abstract}

\section{Introduction}

Replacing missing teeth with dental implants is a common treatment modality with a predictable clinical outcome. A ninety-five percent survival rate after at least 10 years of follow-up has been reported [1]. However, implant associated infection is a common complication of dental implant treatment. There is increasing evidence that infections caused by oral bacteria are frequently a reason for implant failures $[2,3]$. Peri-implantitis is an inflammatory disease that affects both soft tissues and supporting marginal bone around an implant, whereas peri-implant mucositis is a reversible inflammatory reaction restricted only to the peri-implant mucosa $[4,5]$. This inflammatory phenomenon is a result of biofilm formation on the implant surface. Peri-implantitis and peri-implant mucositis have been reported in $18.8 \%$ and $63.4 \%$ of implant patients, respectively [6].

Biofilm formation is a process where microorganisms are irreversibly attached to a surface, interface or to each other, and produce extracellular polymers that facilitate attachment 
and matrix formation $[7,8]$. The surface of transmucosal implant components are exposed to the oral environment containing saliva, gingival crevicular fluid, and microorganisms. Adherence of oral bacteria to solid surfaces is initiated by the adhesion of the early Gram-positive bacterial colonizers such as streptococci, which can further facilitate the binding of secondary bacterial colonizers leading to formation of an anaerobic Gram-negative microbial environment [9]. Streptococcus spp. and Actinomyces naeslundii have been recognized as early colonizers on different implant material surfaces in vivo [10]. More mutans streptococci have been detected around infected implants compared to healthy implant sites [11]. S. mutans is usually associated with caries occurrence, but it is also found in peri-implant biofilms due to its ability to produce an insoluble polymer matrix, survive at low $\mathrm{pH}$ values, and form biofilm with high affinity to solid surfaces such as implant components [12,13].

Treatment of peri-implantitis by mechanical debridement of implant surfaces alone is difficult due to implants having various designs and surface textures. Along with the emergence of multiple antibiotic resistant strains of biofilmassociated microorganisms [14], routine antibiotic treatment is insufficient to eradicate implant associated infections. Prevention of peri-implant mucositis and peri-implantitis should be the primary goal in the management of these conditions. Sound adherence of gingival tissue to implant or abutment surfaces might prevent biofilm formation in periimplant environments. Nanoporous $\mathrm{TiO}_{2}$ coatings have been found to enhance soft tissue attachment on titanium surfaces $[15,16]$. Enhanced tissue adhesion is based on surface reactivity and proper nanotopography which together assist protein adsorption and cellular attachment [17-19]. Furthermore, antibacterial surface modification of implant biomaterials has gained more attention in the prevention of bacterial colonization and biofilm formation [20, 21]. Surface modifications of implant transmucosal components can inhibit bacterial biofilm adhesion [22], which subsequently improve soft tissue attachment $[23,24]$, and preserve alveolar ridge [25]. Among these various modifications, photocatalysis on $\mathrm{TiO} 2$ coating is considered a viable alternative approach to achieve antibacterial activity on biomaterials [26-28].

Photocatalysis of $\mathrm{TiO}_{2}$ coatings on solid surfaces provides self-cleaning, self-sterilizing capabilities, and antibacterial properties through its photoinduced hydrophilicity and decomposition reaction [29]. Photocatalytic $\mathrm{TiO}_{2}$ coatings have been demonstrated to be effective in biomedical applications due to their superhydrophilic and potential bactericidal properties, both induced by UV illumination [30]. When anatase $\mathrm{TiO}_{2}$ is irradiated with ultraviolet light (UV), electron-hole pairs are produced and reactive oxygen species (ROS) are generated. The hole in the valence band can react with water or hydroxide ions adsorbed on the surface to produce hydroxyl radicals $\left(\mathrm{OH}^{-}\right)$and the electron in the conduction band can reduce $\mathrm{O}_{2}$ to generate superoxide ions $\left(\mathrm{O}_{2}{ }^{-}\right)$. These extremely reactive holes can act on the cell walls of nearby bacteria causing cell wall damage and eventually lead to cell death [31]. Several methods have been developed to obtain photocatalytically active $\mathrm{TiO}_{2}$ coatings $[30,32]$. Among these, hydrothermal treatment (HT) has the advantage of being a relatively simple and flexible chemical coating method to produce anatase crystalline $\mathrm{TiO}_{2}$ coating [33]. We have previously shown that HT induced $\mathrm{TiO}_{2}$ surface promotes blood coagulation and human gingival fibroblast attachment. These responses were further improved after UV light activation [34, 35]. However, the same properties that enhance cellular adhesion may promote bacterial cell attachment and subsequent biofilm formation as well. In a previous laboratory experiment with sol-gel derived $\mathrm{TiO}_{2}$ surface treatment, this was however not the case [22]. On the other hand, UV light activation can introduce antimicrobial activity on HT induced $\mathrm{TiO}_{2}$ surfaces, which may inhibit biofilm formation. The purpose of the present study was to explore in vivo early $S$. mutans biofilm formation on HT induced nanoporous $\mathrm{TiO}_{2}$ surfaces and to examine the effect of UV light activation on the biofilm development. We chose $S$. mutans as the test organism since it is present in high counts in peri-implant biofilms. We have previously shown that while HT surface treatment introduces nanoporous $\mathrm{TiO}_{2}$ surface structure it also improves surface wettability, which was demonstrated by lower water contact angles. UV light treatment turns nanoporous $\mathrm{TiO}_{2}$ surfaces superhydrophilic $[34,35]$. Our hypothesis is that these superhydrophilic surfaces hinder S. mutans adhesion and decrease biofilm formation when compared with non-UV treated $\mathrm{HT}$ induced $\mathrm{TiO}_{2}$ or commercially pure titanium surfaces. Furthermore, it is hypothesized that HT induced $\mathrm{TiO}_{2}$ surface per se does not enhance biofilm formation when compared with commercially pure titanium.

\section{Materials and Methods}

2.1. Sample Preparation. Titanium (Ti-6Al-4V) alloy discs with a diameter of $4 \mathrm{~mm}$ and height of $1 \mathrm{~mm}$ were used in this study $(n=40)$. The discs were first ground using silicon carbide grinding paper of 1200 grit with an Ra value of $0.15 \mu \mathrm{m}$, ultrasonically washed with acetone for $5 \mathrm{~min}$ and then in ethanol for $5 \mathrm{~min}$, and dried in air before any surface treatments were carried out. Two main groups, noncoated titanium alloy and nanoporous titanium dioxide surfaces $\left(\mathrm{TiO}_{2}\right)$ obtained by the HT coating method as described earlier, were used as substrates $[34,35]$. In brief, a hydrothermal suspension was prepared by dissolving titanium dioxide $\left(\mathrm{TiO}_{2}\right)$, purified water, 1:10 diluted tetra methyl-ammonium hydroxide (TMAH) $\left(\mathrm{N}\left(\mathrm{CH}_{3}\right)_{4}{ }^{+} \mathrm{OH}\right)^{-}$and mixed for $5 \mathrm{~min}$. Titanium discs were laid at the bottom of Teflon containers consisting of a Teflon inner vessel and a stainless-steel jacket; within this the hydrothermal suspension was added. Then, the vessel was kept at $150 \pm 10^{\circ} \mathrm{C}$ in a constant-temperature oven for $48 \mathrm{~h}$. Subsequent to the hydrothermal treatment period, the titanium discs were removed from the vessel and cooled in air. The discs were washed with distilled water in an ultrasonic bath for $10 \mathrm{~min}$. Then the bottom surfaces of all discs were subjected to sandblasting with large grit aluminum oxide particles $(250-500 \mu \mathrm{m})$ using an air abrasion machine (LM Pro power, Pargas, Finland) to enhance their attachment on the teeth surfaces. The sandblasting process of the samples was performed at distance of $3 \mathrm{~mm}$ for $20 \mathrm{~s}$ 
using 5 bars of air pressure at a $90^{\circ}$ angle. In both groups $(n=20)$ half of the substrates were treated with UV light for 60 min under ambient conditions using a $36 \mathrm{~W}$ puritec HNS germicidal ultraviolet lamp (Osram GmbH; Germany), with a dominant wavelength of $254 \mathrm{~nm}$. Consequently four groups with different surface treatments (one control and three experimental discs) were obtained: noncoated titanium alloy (NC); UV treated noncoated titanium alloy (UVNC); hydrothermally induced $\mathrm{TiO}_{2}$ coating (HT); UV treated titanium alloy with hydrothermally induced $\mathrm{TiO}_{2}$ coating (UVHT). Scanning electron micrographs (SEM) were taken to examine the surface topography of the NC and HT substrate surfaces (Figure 1).

2.2. Subjects, Study Design, and Plaque Collection. In vivo plaque formation on four substrates with different surface treatments was studied in 10 healthy, nonsmoking adult volunteers (6 males, 4 females, mean age 39.7 years, ranging from 25 to 56 years). All the subjects were tested for $S$. mutans by collecting stimulated whole saliva for bacterial cultivation. The UV treatment was administered immediately (fresh surface) before attaching the discs in subjects' molars. Titanium discs were attached on subjects' buccal surfaces of their maxillary molars (Figure 2). The subjects were advised not to brush their teeth and not to use xylitolcontaining products or antimicrobial mouthrinses during the plaque accumulation period. Each subject was advised to maintain their normal diet during the test period, but one day before and during the experiment, sucrose-containing cookies, chocolate, or candies could be consumed 3-5 times a day. This supposedly promoted adhesion of $S$. mutans to the materials [12]. None of the participants used antimicrobial drugs during the study.

The maxillary molars and premolars were professionally cleaned with pumice to remove plaque and pellicle. An area of the size of the specimen on the buccal surface of the tooth was etched with $37 \%$ orthophosphoric acid for $30 \mathrm{~s}$, rinsed, and dried thoroughly. Bonding agent was applied (Scotch bond, 3M ESPE, Deutschland $\mathrm{GmbH}$ ) and then light cured for $10 \mathrm{~s}$. After that the titanium disc was attached on the conditioned tooth surface with light cured flowable composite resin for $20 \mathrm{~s}$ (Filtek ${ }^{\mathrm{TM}}$ Bulk Fill Flowable Restorative, 3M ESPE, Deutschland $\mathrm{GmbH}$ ). Sharp edges were rounded using rotating polishing instruments and water cooling. The adherent plaque was collected according to a previously used method [36]. Briefly, after $24 \mathrm{~h}$ the outer (top) surface of attached titanium was gently rinsed with saline, and plaque was collected by rubbing the surface of each substrate with three applicator sticks (Quick-Stick ${ }^{\circledR}$ Dentsolv AB, Saltsjö-Boo, Sweden) containing approximately $4 \mu \mathrm{l}$ of $\mathrm{NaCl}$ solution. Care was taken not to touch the outer unpolished sides of the discs with the sticks. The tips of the sticks were cut off and collected into a tube containing $900 \mu \mathrm{l}$ of TSB. The samples were stored in $-70^{\circ} \mathrm{C}$ before cultivation. One specimen was lost during plaque collection. A sample of stimulated saliva was collected using a paraffin wax chewing stimulation method for the assessment of salivary counts of S. mutans. Then, $100 \mu \mathrm{l}$ of the saliva was inoculated into $900 \mu \mathrm{l}$ of tryptic soy broth (TSB) and stored as frozen. After plaque collection the specimens were removed, and the excess composite was removed using hand instruments and rotating polishing instruments. Finally, fluoride varnish was applied on the polished enamel surfaces. All clinical procedures were performed by one investigator (NA).

All subjects (10) received all four materials (NC, UVNC, HT, and UVHT) and the surface area of the specimens was equal in all substrates. Titanium discs were randomly distributed among the maxillary first and second molars. Blinding was, however, applied to sample culturing and identification. The primary outcome measures were counts of $S$. mutans, and the secondary outcome measures were total of streptococci or "non-mutans streptococci", which are important biofilm components in early oral biofilm.

2.3. Microbiological Analyses. The microbiological analyses were performed by a laboratory assistant and an experienced microbiologist. Both were blinded as to the sample coding. Cultivation procedure was initiated by thawing and vortexing the transport tubes of the plaque and saliva samples thoroughly. To detach the bacteria from the collection tips, the samples were treated in an ultrasonic bath for $10 \mathrm{~s}$. Ten microlitre aliquots of serial tenfold dilutions of the plaque samples were plated on agar plates. MS were cultured on Mitis salivarius agar containing bacitracin (MSB, Becton, Dickinson and Company, Le Pont de Claix, France) [37].

The plates were incubated for 2 days in a $7 \% \mathrm{CO}_{2}$ atmosphere at $37^{\circ} \mathrm{C}$ and $\mathrm{S}$. mutans was identified on the basis of colony morphology and counted using a stereo microscope. The identification of $S$. mutans and S. sobrinus was performed as described earlier [38, 39]. Low counts of $S$. sobrinus was detected from the samples of only one subject. The counts were combined with $S$. mutans counts. Nonmutans streptococci were cultured for 2 days in air on Mitis salivarius agar at $37^{\circ} \mathrm{C}$. All streptococcal-like colonies were counted as non-mutans streptococci. Total facultatives were cultured for 3 days anaerobically on blood agar (obtained from Turku University Hospital) at $37^{\circ} \mathrm{C}$. All colonies were counted.

2.4. Statistical Analysis. Statistical analysis to compare the number of $S$. mutans CFU among the experimental groups was performed using the SPSS v.23.0 software package (IBM SPSS Inc.), by analyzing the differences among several means, the data were analyzed with one-way analysis of variance (ANOVA) followed by Tukey's post hoc test. Differences were considered significant at a $95 \%$ confidence level, with pvalues below 0.05 .

\section{Results}

Noncoated Ti-6Al-4V (NC) surfaces showed over 2 times more S. mutans in the early biofilm when compared with the hydrothermally (HT) induced nanoporous $\mathrm{TiO}_{2}$ surface. The numbers of colonized surfaces on NC and HT surfaces were equal to 7 and 3 , respectively.

Figure 1 shows SEM images of the substrate surfaces. The NC substrates showed a smooth surface with some grinding 

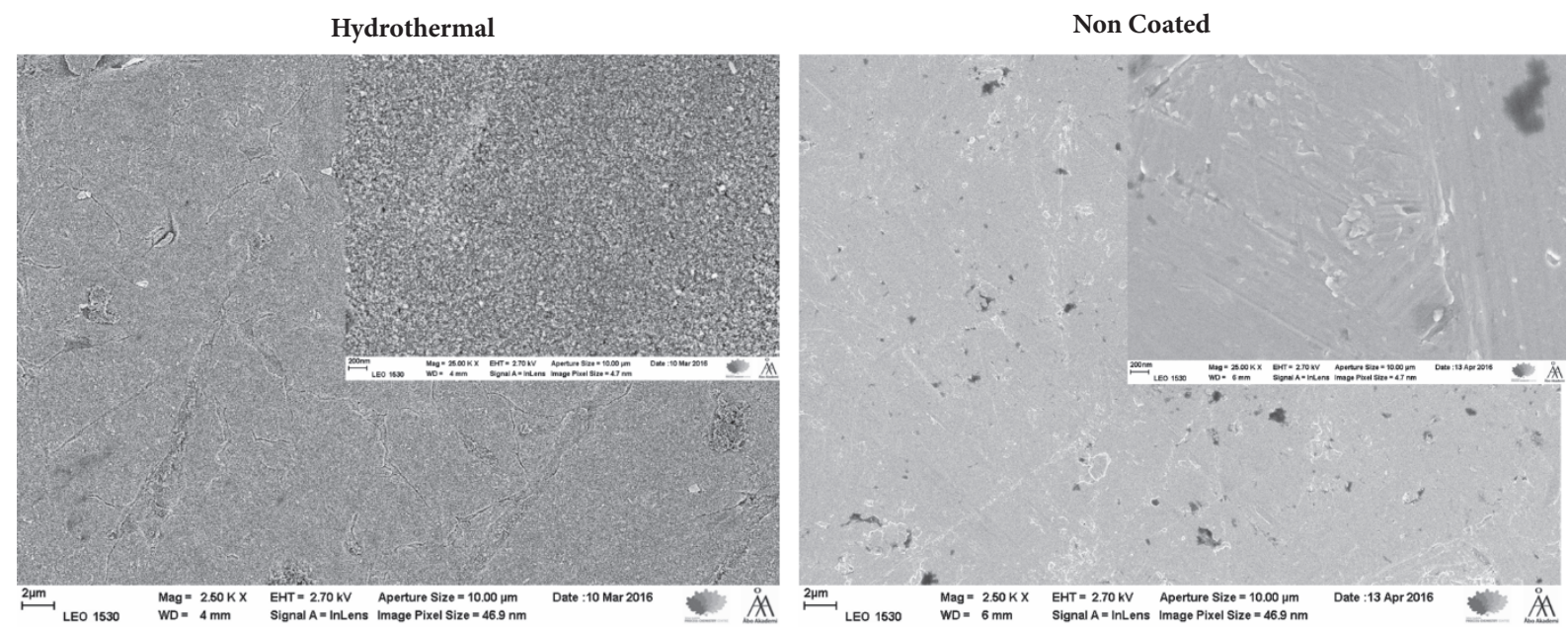

FIGURE 1: SEM images of hydrothermally induced $\mathrm{TiO}_{2}$ coatings and non-coated titanium alloy surfaces at low and high magnification.
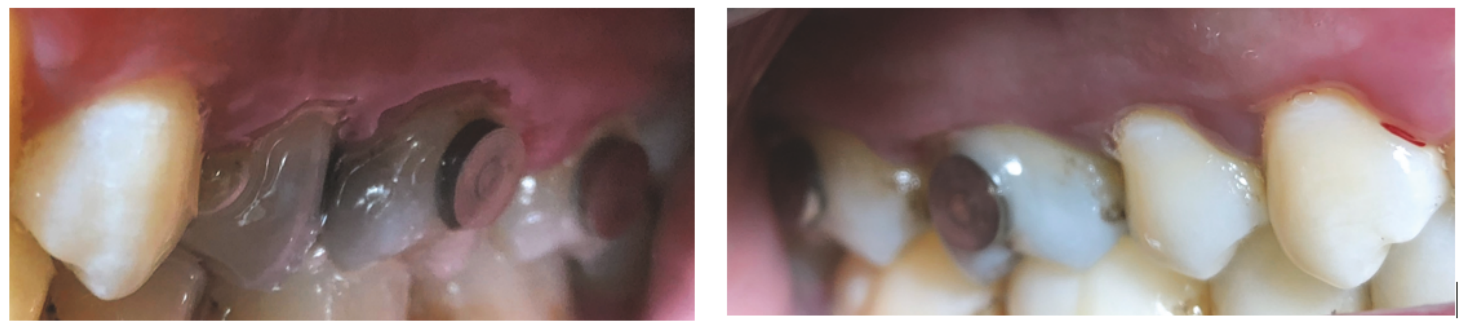

FIGURE 2: Titanium alloy discs attached to the buccal surfaces of maxillary molars.

lines spread out over the surfaces. The HT surfaces had a uniform smooth surface texture fully covered with the coating crystals consisting of nearly spherical nanoparticles of 20-50 nm. The surface did not change in appearance as a result of the UV treatment, and all the UV and NUV have the same surface morphology.

S. mutans was detected in the saliva of 7 out of 10 subjects. Three subjects showed no salivary $S$. mutans counts $(0$ colony-forming units $(\mathrm{CFU}) / \mathrm{ml})$, two showed low counts $\left(<10^{5} \mathrm{CFU} / \mathrm{ml}\right)$, and five showed high counts $\left(>10^{5} \mathrm{CFU} / \mathrm{ml}\right)$. All subjects with salivary $S$. mutans present showed some adherence of it to the studied materials. The distribution of subjects according to $S$. mutans counts found on the studied materials is illustrated in Figure 3. The mean log CFU counts $( \pm \mathrm{SD})$ were $0.35 \pm 0.4$ for NC, $0.07 \pm 0.2$ for HT, $0.25 \pm 0.4$ for UVNC, and $0.16 \pm 0.3$ for UVHT (not statistically significant differences). However after cultivation, the plaque samples of noncoated groups (NC and UVNC) showed more often $S$. mutans in the biofilms than the coated hydrothermal groups (HT and UVHT) with the number of colonized surfaces equal to 7 and 3, respectively.

The results of the microbiological examinations of nonmutans streptococci and total facultative bacteria found from the samples of the studied materials are shown in Figures 4 and 5. No statistically significant differences were found between the groups. UVHT showed the lowest mean for both

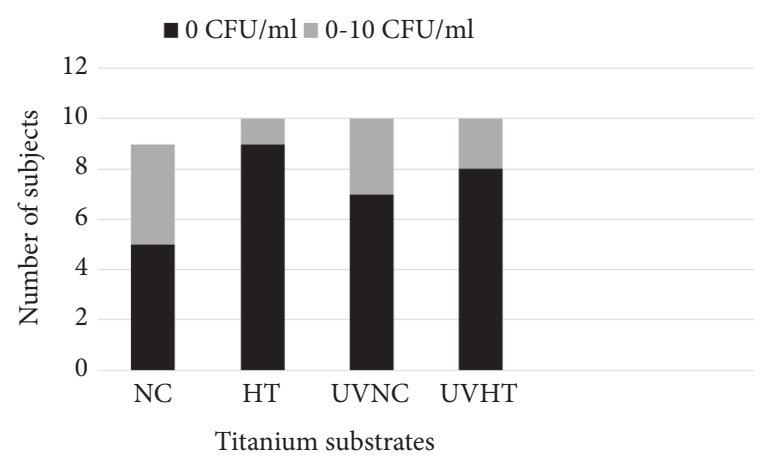

FIGURE 3: Number of subjects having no $(0 \mathrm{CFU} / \mathrm{ml})$ or low $(<10$ $\mathrm{CFU}) \mathrm{MS}$ counts in the plaque collected from the titanium alloy substrates: Non-coated titanium alloy (NC), hydrothermally induced $\mathrm{TiO}_{2}$ coating (HT), UV treated non-coated titanium alloy (UVNC) and UV treated titanium alloy with hydrothermally induced $\mathrm{TiO}_{2}$ coating (UVHT).

non-mutans streptococci and total facultative bacteria counts and NC showed the highest mean counts ( $(5.97 \pm 0.5$ and 6.09 $\pm 0.4)$ and $(6.16 \pm 0.5$ and $6.26 \pm 0.5)$, respectively). This trend was, however, not significant. 


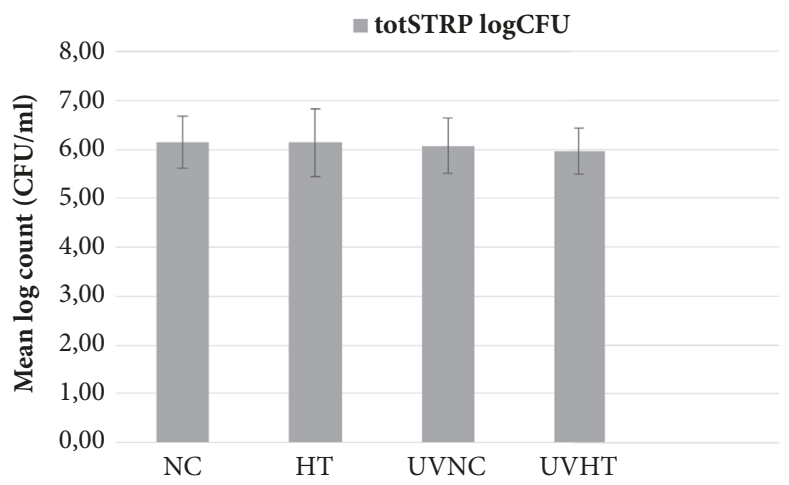

FIGURE 4: Mean logarithmic CFU counts $( \pm$ SD) of non-mutans streptococci in the plaque collected from the studied materials: Non coated titanium alloy (NC), hydrothermally induced $\mathrm{TiO}_{2}$ coating (HT), UV treated non-coated titanium alloy (UVNC) and UV treated titanium alloy with hydrothermally induced $\mathrm{TiO}_{2}$ coating (UVHT).

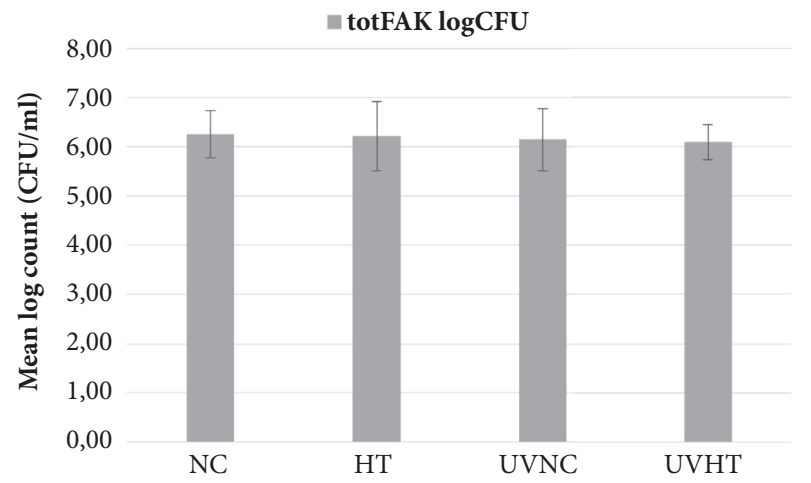

FIGURE 5: Mean logarithmic CFU counts $( \pm S D)$ of total facultative bacteria in the plaque collected from the studied materials: Non coated titanium alloy (NC), hydrothermally induced $\mathrm{TiO}_{2}$ coating (HT), UV treated non-coated titanium alloy (UVNC) and UV treated titanium alloy with hydrothermally induced $\mathrm{TiO}_{2}$ coating (UVHT).

\section{Discussion}

In this study, the hydrothermally induced nanoporous $\mathrm{TiO}_{2}$ surfaces inhibited $S$. mutans adhesion and decreased biofilm formation when compared with noncoated titanium alloy.

The counts of non-mutans streptococci and total facultative bacteria were approximately similar on all studied substrates. In the $24 \mathrm{~h}$ plaque samples, the number of facultatives most likely reflects the number of streptococci. Previous studies have shown that healthy peri-implant sockets are mainly colonized by oral streptococci which constitutes from $45 \%$ to $86 \%$ of supra- and subgingival peri-implant sulcus microbiota. Actinomyces as well as Neisseria and Rothia species have also been frequently isolated [40, 41]. Diaz et al (2006) [42] have found that the initial colonizer on enamel surfaces are mainly streptococci followed by Neisseria pharyngis and Gemella haemolysans. These bacteria were considered by the authors to be a core group, providing the basis for the subsequent colonization of facultative and obligate anaerobes. Similarly, in the present study, streptococci appear to be the predominant species in a $24 \mathrm{~h}$ plaque on the studied substrates.

A microbial biofilm is considered an essential step in the initiation of peri-implant disease [43]. It can be affected by many factors, including local factors of implant and or abutment surface topography, as well as oral environment factors of saliva and protein [44]. The influence of surface properties such as surface roughness and surface chemistry on bacterial adhesion has been largely investigated [45, 46]. The surface roughness has been recognized as the predominant factor for biofilm formation on implant surfaces, as more biofilm is formed on rough modified surfaces compared with smooth surfaces $[41,45]$. In our study the amount of plaque accumulation based on the counts of nonmutans streptococci and total facultative bacteria showed no difference among the experimental groups, which may be explained by surface roughness values of the studied substrates which ranged from 0.15 to $0.2 \mu \mathrm{m}$. These findings are in agreement with a previous study suggesting that a roughness $\left(R_{a}\right)$ value of $0.2 \mu \mathrm{m}$ is a threshold limit below which surface roughness has no major effect on the biofilm formation or colonization [47]. Moreover, in our study the surface roughness of studied substrates was the same before and after UV treatment since the UV treatment did not alter the existing topography, roughness, or other morphologic features [48]. The surface characteristics of implants, such as surface free energy (SFE), and hydrophilicity have been shown to play crucial roles in bacterial adhesion and biofilm formation [49]. High SFE have been shown to attract more microorganisms than low SFE materials. On the contrary, an opposite result has also been reported [50]. A previous in vivo study by Tanner et al. [36], which compared the early plaque formation on different restorative materials, showed that polyethylene, the low SFE material, harboured more microorganisms than higher SFE dental ceramic and restorative composites. It was demonstrated that, in the oral environment, polyethylene fiber reinforced composite (FRC) promotes plaque accumulation and adhesion of $S$. mutans more than glass FRC, restorative composite, and dental ceramic [36]. Our results are in agreement with these findings. We have previously shown that while HT surface treatment introduces nanoporous $\mathrm{TiO}_{2}$ surface structure, it also improves surface wettability, which was demonstrated by lower water contact angles and higher SFE compared to the $\mathrm{NC}$ titanium alloy surface. This $\mathrm{HT}$ induced $\mathrm{TiO}_{2}$ surface also promotes blood coagulation and human gingival fibroblast attachment $[34,35]$. The results of the microbiological examinations in the present study showed no statistically significant differences among the experimental groups. Our results seem to be in agreement with Rochford et al. [51] who showed that SFE can be improved on implant surfaces for better osseointegration without leading to more bacteria adhesion.

The nanoscale modification of the implant surface has been widely investigated. This surface modification can alter the surface chemistry and topography of an implant surface, which influences the initial cell response at the cell-material interface and improves bioactivity and bactericidal properties 
$[22,52]$. In our study HT samples showed almost no S. mutans in the biofilms, whereas $S$. mutans was found on nearly half of NC samples after cultivation. The plaque samples of noncoated groups (NC, UVNC) harboured more frequently S. mutans in the biofilm than the coated hydrothermal groups (HT, UVHT) with the number of colonized surfaces being equal to 7 and 3, respectively. UV treated $\mathrm{TiO}_{2}$ surfaces have demonstrated superhydrophilicity, stain-proofing properties, and bactericidal properties [29, 53, 54]. Furthermore UV light treatment on various topographical titanium surfaces has been shown to reduce the biofilm formation of wound pathogens [55]. In our result, plaque recovered from the UVHT samples showed the lowest counts for both nonmutans streptococci and total facultative bacteria counts whereas NC samples showed the highest counts, although the differences were not significant and the real antimicrobial effect of UV treatment could not be confirmed in an oral environment. These findings, however, are in accordance with the in vitro study by Gallarado-Moreno et al. (2009) [56] who reported that UV treatment of Ti-6Al-4V inhibits bacterial attachment without compromising the osteoblast cell response to this alloy. This is probably related to the fact that UV treatment converts already hydrophilic nanostructured Ti alloy surfaces to superhydrophilic and cleans the contaminated hydrocarbons that accumulate on titanium surfaces [54].

The number of subjects (10) in the present study is relatively low. HT induced $\mathrm{TiO}_{2}$ surfaces and UV light treatment seem to reduce bacterial colonization, but much larger number of subjects will be needed for thorough statistical evaluation. On the other hand, the clinical importance should be seen in this number of subjects. The possibility of adding an in situ self-cleaning and antibacterial feature to $\mathrm{HT}$ induced $\mathrm{TiO}_{2}$ surfaces with UV light treatment could minimize implant infection related complications.

\section{Conclusions}

The results of this experimental in vivo study suggested that hydrothermally induced nanoporous $\mathrm{TiO}_{2}$ surface, which we earlier showed to improve blood coagulation and encourage human gingival fibroblast attachment in vitro, does not enhance salivary microbial (mostly mutans streptococci) adhesion and initial biofilm formation when compared with noncoated Ti-6Al-4V surfaces. UV light treatment provided Ti-6Al-4V surfaces with antibacterial properties and showed a trend towards less biofilm formation when compared with non-UV treated titanium surfaces.

\section{Data Availability}

The raw data used to support the findings of this study are available from the corresponding author upon request.

\section{Conflicts of Interest}

The authors declare that they have no conflicts of interest with respect to the authorship and/or publication of this article.

\section{Acknowledgments}

The authors gratefully acknowledge Ms. Katja Sampalahti (Institute of Dentistry, University of Turku) for her skillful technical assistance. The corresponding author wishes to thank the Libyan Ministry of Education for its scholarship support. This study was supported by ITI Grant no. 1256_2017.

\section{References}

[1] L. Hjalmarsson, M. Gheisarifar, and T. Jemt, "A systematic review of survival of single implants as presented in longitudinal studies with a follow-up of at least 10 years," European Journal of Oral Implantology, vol. 9 (suppl 1), pp. 155-162, 2016.

[2] M. Esposito, J.-M. Hirsch, U. Lekholm, and P. Thomsen, "Biological factors contributing to failures of osseointegrated oral implants. (I). Success criteria and epidemiology," European Journal of Oral Sciences, vol. 106, no. 1, pp. 527-551, 1998.

[3] A. Mombelli and N. P. Lang, "The diagnosis and treatment of peri-implantitis," Periodontology 2000, vol. 17, no. 1, pp. 63-76, 1998.

[4] J. Lindhe and J. Meyle, "Peri-implant diseases: consensus report of the sixth European Workshop on Periodontology," Journal of Clinical Periodontology, vol. 35, no. 8, pp. 282-285, 2008.

[5] N. P. Lang, T. G. Wilson, and E. F. Corbet, "Biological complications with dental implants: their prevention, diagnosis and treatment," Clinical Oral Implants Research, vol. 11, pp. 146-155, 2000.

[6] M. A. Atieh, N. H. M. Alsabeeha, C. M. Faggion Jr., and W. J. Duncan, "The frequency of peri-implant diseases: a systematic review and meta-Analysis," Journal of Periodontology, vol. 84, no. 11, pp. 1586-1598, 2013.

[7] R. M. Donlan and J. W. Costerton, "Biofilms: survival mechanisms of clinically relevant microorganisms," Clinical Microbiology Reviews, vol. 15, no. 2, pp. 167-193, 2002.

[8] W. M. Dunne Jr., "Bacterial adhesion: seen any good biofilms lately?” Clinical Microbiology Reviews, vol. 15, no. 2, pp. 155-166, 2002.

[9] P. E. Kolenbrander, R. J. Palmer Jr., A. H. Rickard, N. S. Jakubovics, N. I. Chalmers, and P. I. Diaz, "Bacterial interactions and successions during plaque development," Periodontology 2000, vol. 42, no. 1, pp. 47-79, 2006.

[10] M. Al-Ahmad, J. Faust, M. Bächle et al., "Biofilm formation and composition on different implant materials in vivo," Journal of Biomedical Materials Research Part B: Applied Biomaterials, vol. 95, no. 1, pp. 101-109, 2010.

[11] P. S. Kumar, M. R. Mason, M. R. Brooker, and K. O’Brien, "Pyrosequencing reveals unique microbial signatures associated with healthy and failing dental implants," Journal of Clinical Periodontology, vol. 39, no. 5, pp. 425-433, 2012.

[12] H. Koo, M. L. Falsetta, and M. I. Klein, “The exopolysaccharide matrix: a virulence determinant of cariogenic biofilm," Journal of Dental Research, vol. 92, no. 12, pp. 1065-1073, 2013.

[13] S. Tamura, H. Yonezawa, M. Motegi et al., "Inhibiting effects of Streptococcus salivarius on competence-stimulating peptidedependent biofilm formation by Streptococcus mutans," Oral microbiology and immunology, vol. 24, no. 2, pp. 152-161, 2009.

[14] P. S. Stewart and J. W. Costerton, "Antibiotic resistance of bacteria in biofilms," The Lancet, vol. 358, no. 9276, pp. 135-138, 2001. 
[15] S. Areva, H. Paldan, T. Peltola, T. Närhi, M. Jokinen, and M. Lindén, "Use of sol-gel-derived titania coating for direct soft tissue attachment," Journal of Biomedical Materials Research Part A, vol. 70, no. 2, pp. 169-178, 2004.

[16] H. Paldan, S. Areva, and T. Tirri, "Soft tissue attachment on sol-gel-treated titanium implants in vivo," Journal of Materials Science: Materials in Medicine, vol. 19, no. 3, pp. 1283-1290, 2008.

[17] L. Guida, A. Oliva, M. A. Basile, M. Giordano, L. Nastri, and M. Annunziata, "Human gingival fibroblast functions are stimulated by oxidized nano-structured titanium surfaces," Journal of Dentistry, vol. 41, no. 10, pp. 900-907, 2013.

[18] S. Areva, T. Peltola, E. Säilynoja, K. Laajalehto, M. Lindén, and J. B. Rosenholm, "Effect of albumin and fibrinogen on calcium phosphate formation on sol-gel-derived titania coatings in vitro," Chemistry of Materials, vol. 14, no. 4, pp. 1614-1621, 2002.

[19] V. V. Meretoja, S. Rossi, T. Peltola, L. J. Pelliniemi, and T. O. Närhi, "Adhesion and proliferation of human fibroblasts on solgel coated titania," Journal of Biomedical Materials Research Part A, vol. 95, no. 1, pp. 269-275, 2010.

[20] J. B. Brunski, D. A. Puleo, and A. Nanci, "Biomaterials and biomechanics of oral and maxillofacial implants: current status and future developments," International Journal of Oral \& Maxillofacial Implants, vol. 15, no. 1, pp. 15-46, 2000.

[21] F. Heidenau, W. Mittelmeier, R. Detsch et al., "A novel antibacterial titania coating: Metal ion toxicity and in vitro surface colonization," Journal of Materials Science: Materials in Medicine, vol. 16, no. 10, pp. 883-888, 2005.

[22] V. Fröjd, P. Linderbäck, A. Wennerberg, L. Chávez de Paz, G. Svensäter, and J. R. Davies, "Effect of nanoporous $\mathrm{TiO}_{2}$ coating and anodized $\mathrm{Ca}^{2+}$ modification of titanium surfaces on early microbial biofilm formation," BMC Oral Health, vol. 11, no. 8, 2011.

[23] N. Hoshi, H. Negishi, S. Okada, T. Nonami, and K. Kimoto, "Response of human fibroblasts to implant surface coated with titanium dioxide photocatalytic films," Journal of Prosthodontic Research, vol. 54, no. 4, pp. 185-191, 2010.

[24] S. Werner, O. Huck, B. Frisch et al., "The effect of microstructured surfaces and laminin-derived peptide coatings on soft tissue interactions with titanium dental implants," Biomaterials, vol. 30, no. 12, pp. 2291-2301, 2009.

[25] S. Botos, H. Yousef, B. Zweig, R. Flinton, and S. Weiner, “The effects of laser microtexturing of the dental implant collar on crestal bone levels and peri-implant health," The International Journal of Oral \& Maxillofacial Implants, vol. 26, no. 3, pp. 492498, 2011.

[26] H. A. Foster, I. B. Ditta, S. Varghese, and A. Steele, "Photocatalytic disinfection using titanium dioxide: spectrum and mechanism of antimicrobial activity," Applied Microbiology and Biotechnology, vol. 90, no. 6, pp. 1847-1868, 2011.

[27] D. J. Riley, V. Bavastrello, U. Covani, A. Barone, and C. Nicolini, "An in-vitro study of the sterilization of titanium dental implants using low intensity UV-radiation," Dental Materials, vol. 21, no. 8, pp. 756-760, 2005.

[28] E. Unosson, E. K. Tsekoura, H. Engqvist, and K. Welch, "Synergetic inactivation of Staphylococcus epidermidis and Streptococcus mutansin a TiO2/H2O2/UV system," Biomatter, vol. 3, no. 4, 2013.

[29] A. Fujishima, X. Zhang, and D. A. Tryk, " $\mathrm{TiO}_{2}$ photocatalysis and related surface phenomena," Surface Science Reports, vol. 63, no. 12, pp. 515-582, 2008.

[30] F. Rupp, M. Haupt, H. Klostermann et al., "Multifunctional nature of UV-irradiated nanocrystalline anatase thin films for biomedical applications," Acta Biomaterialia, vol. 6, no. 12, pp. 4566-4577, 2010.

[31] P.-C. Maness, S. Smolinski, D. M. Blake, Z. Huang, E. J. Wolfrum, and W. A. Jacoby, "Bactericidal activity of photocatalytic $\mathrm{TiO}_{2}$ reaction: toward an understanding of its killing mechanism," Applied and Environmental Microbiology, vol. 65, no. 9, pp. 4094-4098, 1999.

[32] E. Unosson, C. Persson, K. Welch, and H. Engqvist, "Photocatalytic activity of low temperature oxidized Ti-6Al-4V," Journal of Materials Science: Materials in Medicine, vol. 23, no. 5, pp. 1173-1180, 2012.

[33] M. Nakagawa, L. Zhang, K. Udoh, S. Matsuya, and K. Ishikawa, "Effects of hydrothermal treatment with $\mathrm{CaCl} 2$ solution on surface property and cell response of titanium implants," Journal of Materials Science: Materials in Medicine, vol. 16, no. 11, pp. 985991, 2005.

[34] N. Areid, I. Kangasniemi, E. Söderling, and T. O. Närhi, "Ultraviolet photofunctionalization of nanostructured titanium surfaces enhances thrombogenicity and platelet response," Journal of Materials Science: Materials in Medicine, vol. 29, no. 5, 2018.

[35] N. Areid, A. Peltola, I. Kangasniemi, A. Ballo, and T. O. Närhi, "Effect of ultraviolet light treatment on surface hydrophilicity and human gingival fibroblast response on nanostructured titanium surfaces," Clinical and Experimental Dental Research, vol. 4, no. 3, pp. 78-85, 2018.

[36] J. Tanner, C. Robinson, E. Söderling, and P. Vallittu, "Early plaque formation on fibre-reinforced composites in vivo," Clinical Oral Investigations, vol. 9, no. 3, pp. 154-160, 2005.

[37] O. G. Gold, H. V. Jordan, and J. van Houte, "A selective medium for Streptococcus mutans," Archives of Oral Biolog, vol. 18, no. 11, pp. 1357-1364, 1973.

[38] T. Fujiwara, E. Sasada, N. Mima, and T. Ooshima, "Caries prevalence and salivary mutans streptococci in 0-2-year-old children of Japan," Community Dentistry and Oral Epidemiology, vol. 19, no. 3, pp. 151-154, 1991.

[39] E. Söderling, P. Isokangas, K. Pienihäkkinen, and J. Tenovuo, "Influence of maternal xylitol consumption on acquisition of mutans streptococci by infants," Journal of Dental Research, vol. 79, no. 3, pp. 882-887, 2000.

[40] M. Quirynen, R. Vogels, M. Pauwels et al., "Initial subgingival colonization of 'pristine' pockets," Journal of Dental Research, vol. 84, no. 4, pp. 340-344, 2005.

[41] C. Elter, W. Heuer, and A. Demling, "Supra- and subgingival biofilm formation on implant abutments with different surface characteristics," The International Journal of Oral \& Maxillofacial Implants, vol. 23, no. 2, pp. 327-334, 2008.

[42] P. I. Diaz, N. I. Chalmers, A. H. Rickard et al., "Molecular characterization of subject-specific oral microflora during initial colonization of enamel," Applied and Environmental Microbiology, vol. 72, no. 4, pp. 2837-2848, 2006.

[43] F. Costa, I. F. Carvalho, R. C. Montelaro, P. Gomes, and M. C. L. Martins, "Covalent immobilization of antimicrobial peptides (AMPs) onto biomaterial surfaces," Acta Biomaterialia, vol. 7, no. 4, pp. 1431-1440, 2011.

[44] M. Katsikogianni and Y. F. Missirlis, "Concise review of mechanisms of bacterial adhesion to biomaterials and of techniques used in estimating bacteria-material interactions," European Cells \& Materials, vol. 8, pp. 37-57, 2004.

[45] R. Bürgers, T. Gerlach, S. Hahnel, F. Schwarz, G. Handel, and M. Gosau, "In vivo and in vitro biofilm formation on two different 
titanium implant surfaces," Clinical Oral Implants Research, vol. 21, no. 2, pp. 156-164, 2010.

[46] W. Teughels, N. Van Assche, I. Sliepen, and M. Quirynen, "Effect of material characteristics and/or surface topography on biofilm development," Clinical Oral Implants Research, vol. 17, no. 2, pp. 68-81, 2006.

[47] C. M. L. Bollen, W. Papaioanno, J. Van Eldere, E. Schepers, M. Quirynen, and D. Van Steenberghe, "The influence of abutment surface roughness on plaque accumulation and peri-implant mucositis," Clinical Oral Implants Research, vol. 7, no. 3, pp. 201211, 1996.

[48] H. Aita, W. Att, T. Ueno et al., "Ultraviolet light-mediated photofunctionalization of titanium to promote human mesenchymal stem cell migration, attachment, proliferation and differentiation," Acta Biomaterialia, vol. 5, no. 8, pp. 3247-3257, 2009.

[49] M. Quirynen and C. M. Bollen, "The influence of surface roughness and surface-free energy on supra- and subgingival plaque formation in man. A review of the literature.," Journal of Clinical Periodontology, vol. 22, no. 1, pp. 1-14, 1995.

[50] N. Villard, C. Seneviratne, J. K. H. Tsoi, M. Heinonen, and J. Matinlinna, "Candida albicans aspects of novel silane systemcoated titanium and zirconia implant surfaces," Clinical Oral Implants Research, vol. 26, no. 3, pp. 332-341, 2015.

[51] E. T. J. Rochford, G. Subbiahdoss, T. F. Moriarty et al., "An in vitro investigation of bacteria-osteoblast competition on oxygen plasma-modified PEEK," Journal of Biomedical Materials Research Part A, vol. 102, no. 12, pp. 4427-4434, 2014.

[52] A. P. Tomsia, J. S. Lee, U. G. K. Wegst, and E. Saiz, "Nanotechnology for dental implants," The International Journal of Oral \& Maxillofacial Implants, vol. 28, no. 6, pp. e535-e546, 2013.

[53] N. Suketa, T. Sawase, H. Kitaura et al., "An antibacterial surface on dental implants, based on the photocatalytic bactericidal effect," Clinical Implant Dentistry and Related Research, vol. 7, no. 2, pp. 105-111, 2005.

[54] H. Aita, N. Hori, M. Takeuchi et al., "The effect of ultraviolet functionalization of titanium on integration with bone," Biomaterials, vol. 30, no. 6, pp. 1015-1025, 2009.

[55] Y. Yamada, M. Yamada, T. Ueda, and K. Sakurai, "Reduction of biofilm formation on titanium surface with ultraviolet-C preirradiation," Journal of Biomaterials Applications, vol. 29, no. 2, pp. 161-171, 2014.

[56] A. M. Gallardo-Moreno, M. A. Pacha-Olivenza, L. Saldaña et al., "In vitro biocompatibility and bacterial adhesion of physico-chemically modified Ti6Al4V surface by means of UV irradiation," Acta Biomaterialia, vol. 5, no. 1, pp. 181-192, 2009. 


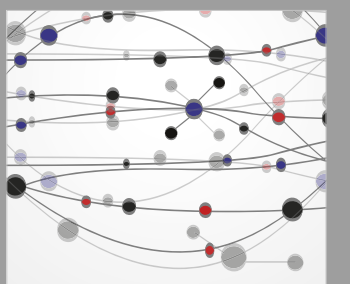

The Scientific World Journal
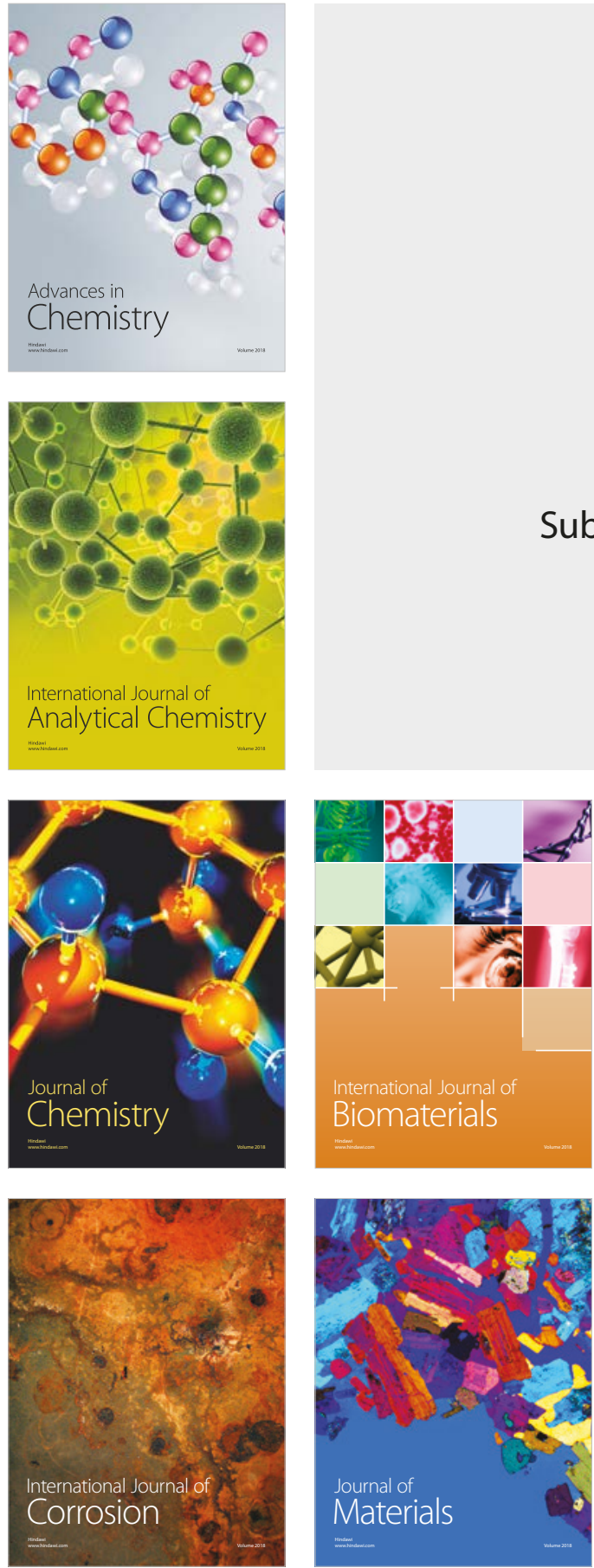

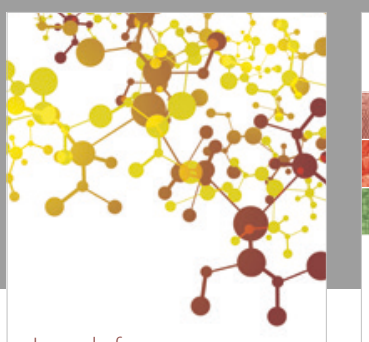

Journal of

Applied Chemistry
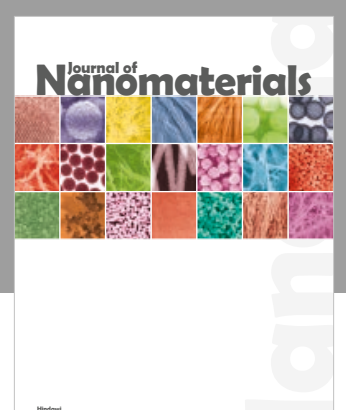

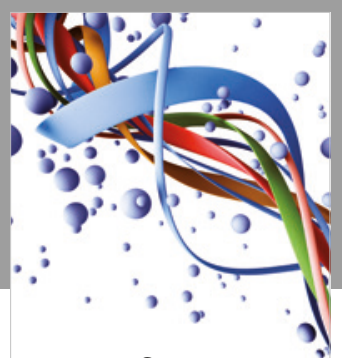

Scientifica

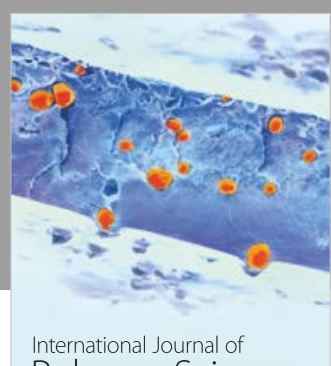

Polymer Science

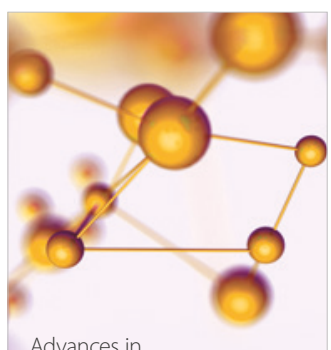

Physical Chemistry
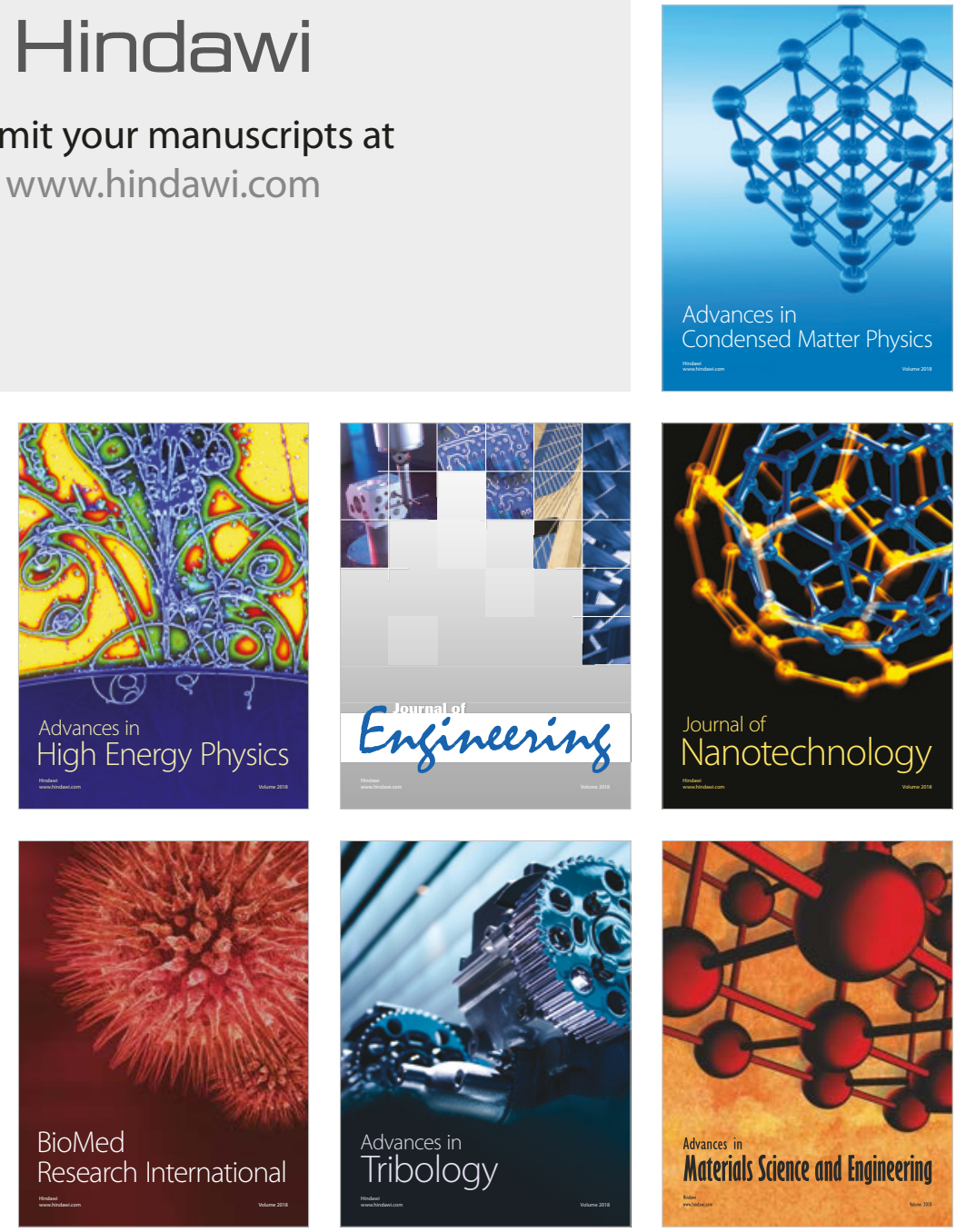